\title{
Structural and Technological Features of an Installation for Recovery of End-of-life Automobile Tires
}

\author{
Violeta Rasheva ${ }^{1, *}$, Georgi Komitov ${ }^{2}$, Ivan Binev $^{3}$, and Georgi Valtchev ${ }^{1}$ \\ ${ }^{1}$ Department of Industrial Thermal Engineering, University of Food Technologies, Plovdiv, Bulgaria \\ ${ }^{2}$ Department of Agricultural Mechanization, Agricultural University, Plovdiv, Bulgaria \\ ${ }^{3}$ Department of Energetics, Trakia University St. Zagora, Faculty of Technics and Technology, Bulgaria
}

\begin{abstract}
Automobile tires are one of the generated wastes from the road transport. According to an EU directive after 2006, end-of-life tires are subject to controlled collection and storage by traders. Direct incineration is unacceptable due to high levels of hazardous emissions. In addition to the high rate of depletion of natural resources, and in line with the "sustainable development" model, it is appropriate to create new advanced technologies for the proper utilization of natural resources through the reuse of end-of-life products. The pyrolysis technology of decomposition of raw materials is an innovative technology for production of fuels and metals from the disposal tires. This technology shows a reduced risk to public health and reduced levels of harmful substances in flue gases, has low operating costs and does not require separate waste collection. This paper focuses on the structural features of the pyrolysis installation for used automobile tires recycling. The installation has been implemented into production and has a capacity of 1 ton of end-of-life tires per hour. The result is $400 \mathrm{~kg}$ of liquid fuel, $400 \mathrm{~kg}$ of carbon and $100 \mathrm{~kg}$ of metal waste per hour.
\end{abstract}

\section{Introduction}

Global warming is becoming a serious problem. According to the latest research and the need for urgent action to combat climate change, the European Council supports the objective of achieving a neutral climate impact of the EU by 2050, in accordance with the Paris Agreement. The transition to the neutral climate will bring significant opportunities such as potential for economic growth, new business models and markets, new jobs and technological development. However, achieving climate neutrality will require overcoming serious challenges and significant investment. The European Council recognizes the need to ensure energy security and respects the right of Member States to choose the most appropriate technologies [1].

Due to the global policy on $\mathrm{CO}_{2}$ emissions reduction, governments, municipalities and operators of industrial and commercial installations are looking for ways to use energy more efficiently [2]. A number of scientists have focused their research in this area [3-5].

\footnotetext{
* Corresponding author: v_rasheva@abv.bg
} 
The daily human activity is related to the generation of waste. The issue of environmental solid waste disposal is still being addressed. Waste is not only a threat to humans, but also a resource through the proper processing of which the use of raw materials for energy generation could be minimized. The policy on waste management in the European Union (EU) aims to reduce their impact on the environment and human health, and to promote the efficient use of resources. In the long term, the goal is to make Europe a recycling society that prevents waste generation and uses inevitable waste as much as possible as resources. The aim is to achieve a higher level of recycling and to minimize the use of additional natural resources. EU waste management policy is regulated in a number of directives and regulations [6-8]. The end-of-life tyres (ELTs) within the EU are managed by three different models as follows: extended producer responsibility (EPR), liberal system (free market) and the tax system (government responsibility, financed through a tax) [9].

In Bulgaria, the Waste management act (WMA) regulates the hierarchy of waste management: prevention, recovery (recycling, reuse and/or recovery of recyclable materials and energy from waste that cannot be prevented) and disposal [10]. According to the WMA, the cost of collecting, transporting, utilizing and disposing of waste should be at the expense of the owners and producers of the waste, which is in accordance with the principles "polluter pays" and "producer responsibility".

The industrialization and growing global population have led to an increase in the number of road vehicles which in turn results in an increase in ELTs [11-14]. Annually, 1 billion tires, $40 \%$ of which are heavy truck tires, are dumped at landfills where they pile up due to their non-degradable nature, creating a problem for the environment. At the same rate of production, the problem increases with each passing day, forcing researchers to find alternatives to discarding and for utilizing energy as tires are a good source of carbon fuel [15].

Disposing of used tires is an important environmental issue in terms of the huge spaces turned into dumps and other related problems such as poor biodegradability, easy self-ignition causing long-lasting fires, stagnant water spreading insects and risk of infection [16].

According to the waste hierarchy, tires' recycling is most preferred in terms of waste management. However, the use of recycled tires is not well received. The recovery of energy from ELTs through their burning in cement kilns is becoming unacceptable in view of the increasingly stringent emissions requirements [17].

Tires contain valuable components, such as carbon black, organic oils and steel, but their extraction in a cost effective manner is extremely difficult. Only a few of the ELTs recovery technologies are viable, while others have not been used on an industrial scale yet [18].

Granulation is a recent sector. Rubber granules, obtained from fine ground tires could be used for production of various products. It seems that the use of rubber granules in civil engineering and other applications is a good approach, proven by a number of successful cases. Apart from lightweight, good thermal insulation and good drainage properties of shredded tires, rubber also possesses excellent vibration absorption capability, which has not been fully exploited yet. This property is expected to be useful in reducing vibrations and earthquake protection [16].

However, there is little evidence of occupational exposure and associated pathologies. More research should be carried out on the levels of inhalation exposure to the particles produced during granulation and the atmospheric pollutants in the workshops [19].

Many tire recycling options have been used, such as repairing, grinding and incineration. However, these processes have their limitation and do not fully utilize ELTs as an excellent material and energy recovery [20]. For this reason, the pyrolysis of ELTs has received new attention for the production of valuable products. The pyrolysis process is both environmentally friendly and technologically feasible for the recycling of ELTs [21]. The method involves thermal decomposition of waste rubber in the absence of oxygen, producing oil, carbon, gas, steel and residual products from waste tires. The oil obtained from the ELTs pyrolysis could be used as an alternative diesel or as a source for production of chemicals [22-23]. 
Currently, many researchers have focused their works on the thermal behaviour of the pyrolysis of ELTs crumb and whole tires. Pyrolysis proved to be a feasible alternative to deal with the problem of scrap tire disposal. The process yielded $46 \%$ of oil, $40 \%$ of activated carbon and $14 \%$ of gases, which could be used as a source of heat in the pyrolysis process. As for the pyrolysis, the higher the temperature and the lower the pressure the higher the fuel oil yield [24]. It could be seen that the waste tire rubber is not completely decomposed at the temperature less than $500^{\circ} \mathrm{C}$. The optimum conditions for the process are at temperature of $500{ }^{\circ} \mathrm{C}, 80$ mesh particle size and $5 \mathrm{~L} / \mathrm{min}$ carrier gas flow rate to achieve the highest yield of pyrolysis oil [25]. The technology of pyrolysis, based on using the whole tires significantly reduces the disposal costs of expenses incurred for its grinding, according to [26]. Variation in process parameters at small and laboratory pilot scale ensure that the total conversion of rubber tire does not register significant changes. It is found that the three obtained products (gas, liquid and solid fractions) have a good energetic potential: the solid $(20-32 \mathrm{MJ} / \mathrm{kg})$, the liquid (41 $43 \mathrm{MJ} / \mathrm{kg}$ ) and the gas $\left(32-36 \mathrm{MJ} / \mathrm{m}^{3}\right)$. Nevertheless, the liquid needs to be refined in order to be used as diesel-like fuel and gases should be treated to remove sulphur compounds [27].

This paper focuses on building of an installation for pyrolysis treatment of end-of-life automobile tires in Bulgaria.

\section{Description of the plant}

The installation is designed according to the innovative technology for recovery of materials and energy from ELTs [28], the scheme of which is shown in Figure 1.

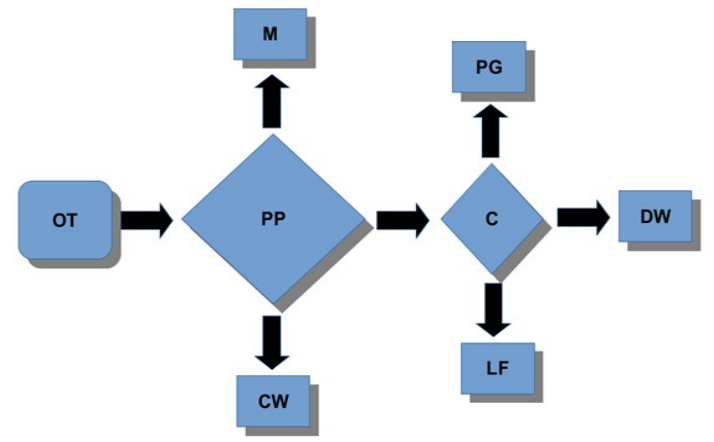

Fig. 1. Flow diagram of ELTs pyrolysis process: OT - old tires; PP - pyrolysis process; $M$ - metal residue; CW - carbon residue; C - condensation; LF - liquid fuel; PG-pyrolysis gas; DW - domestic hot water

The general view of the installation for pyrolysis of ELTs is shown in Figure 2 and has been developed with a view to simplify the design and facilitate the maintenance of the system.

The plant has capacity of 1 ton raw material (ELTs) per hour. Its core modules are a pyrolysis boiler (5), a mixing heat exchanger (8), a pyrolysis gas condenser with a water jacket (9) and a module for cooling the solid carbon obtained from the pyrolysis (25).

The pyrolysis boiler is fed through a system of conveyors. The ELTs are fed to the conveyor 1 . The loading is organized either by pouring them directly from the truck on a ramp above the conveyor or by a forklift. The conveyor is inclined so that it can feed the next unit in the system - shredder (2). The function of shredder is to fragment tires to a certain size, suitable for further processing. Fragmentation is necessary in order to reduce the size of tires and to facilitate their decomposition in the pyrolysis. The size of the shredded tires should be determined experimentally according to the capabilities of the pyrolysis boiler and its supply system. The fragmented tires are fed to another inclined conveyor (3), at the end of which there is a rotor valve. This valve is required to supply the specified amount of shredded tires to the pyrolysis boiler and to establish a steady pyrolysis process. The tires from the outlet 
of the rotor valve are fed to the auger conveyor (4). The auger speed is adjusted by a worm gearbox attached to the auger. The speed of rotation of the $s$ auger is determined by the speed of the metal conveyor in the pyrolysis boiler and by the open position of the rotor valve.

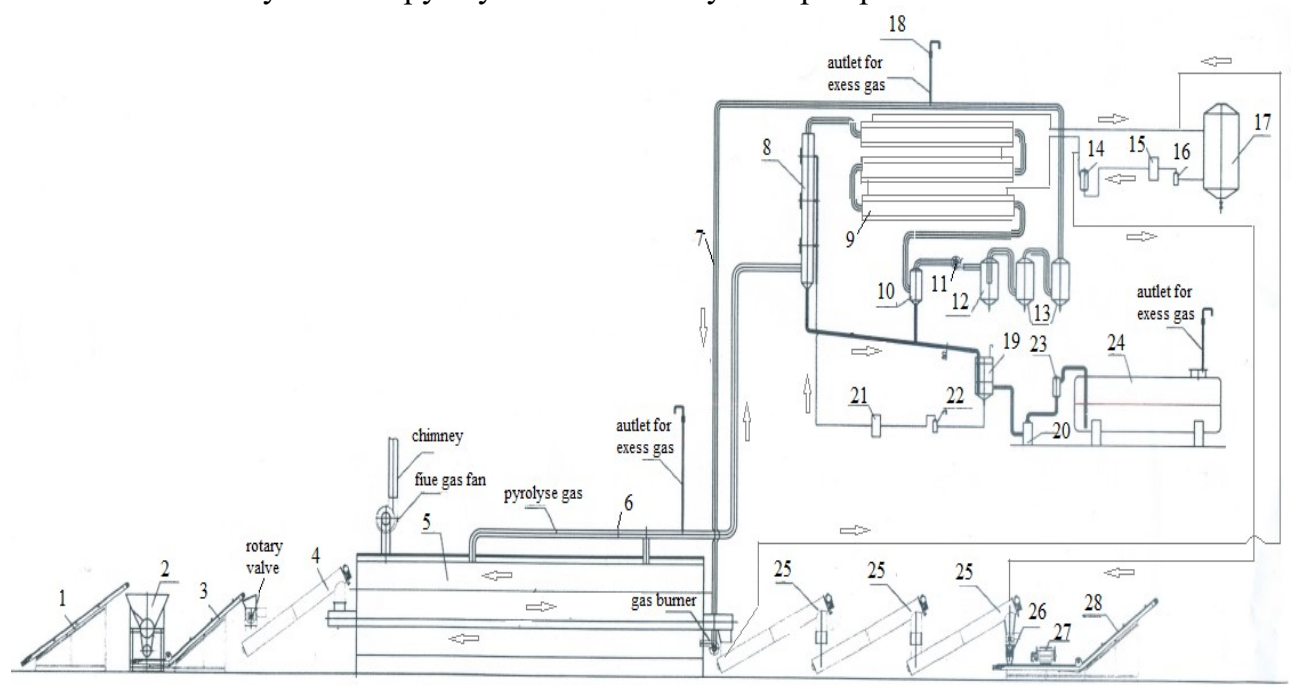

Fig. 2. General view of the plant for utilization of valuable materials from ELTs: 1 - inclined conveyor; 2 - shredder; 3 - inclined conveyor with rotary valve; 4 - auger conveyor; 5 - pyrolysis boiler; 6 - output pipes for pyrolysis gas; 7 - gaseous fuel inlet to the pyrolysis boiler burner; 8 - mixing heat exchanger; 9 - condenser with water jacket; 10 - gas/liquid separator; 11 - fan; 12 - centrifugal separator; 13 - gas receivers; 14 - water filter; 15 - refrigeration machine; 16 - circulation water pump; 17 - water tank; 18 - fire barrier; 19 - intermediate fuel tank; 20 - circulating fuel pump; 21 - cooler for liquid fuel; 22 - fuel pump; 23 - fuel filter; 24 - liquid fuel tank; 25 - auger conveyor with water jacket; 26 - crusher of carbon; 27 - magnetic separator; 28 - outgoing conveyor

The shredded tires are heated to $600^{\circ} \mathrm{C}$ in an oxygen-free environment and a vacuum of 0.2 bars in the pyrolysis boiler. The tires are heated by a gas burner fueled by pyrolysis gas obtained in the same installation. The parameters of this gas are flow rate $100 \mathrm{~kg} / \mathrm{h}$ and a temperature of $40^{\circ} \mathrm{C}$. The flue gas resulting from the combustion moves counter currently to the metal conveyor for tires pieces in the pyrolysis boiler and leave it sucked by an explosion-proof fan through the chimney. As a result of the pyrolysis, the pieces of tires decompose into pyrolysis gas and solid carbon residue. The pyrolysis gas leaves the boiler at a temperature of $600^{\circ} \mathrm{C}$ and flow rate $500 \mathrm{~kg} / \mathrm{h}$ through the pipelines (6), secured by an outlet of excess gas and a fire barrier.

The solid residue is discharged from the boiler through its metal conveyor and fed to an auger conveyor with a water jacket (25), a general view of which is shown in Figure 3. The auger is inclined at an angle of $25^{\circ}$ for a more convenient transfer of the solid residue and to save area. The solid residue enters the inlet of auger conveyor at a temperature of $600^{\circ} \mathrm{C}$ and a flow rate of $500 \mathrm{~kg} / \mathrm{h}$ and passes through three auger conveyors (25) to be cooled to a temperature of $40^{\circ} \mathrm{C}$.

The solid residue contains carbon and metal particles from the tire frame. Because of that after being cooled, it is fed to the carbon crusher (26) and is crushed into finer parts for better separation of the metal from it. Usually the crushing takes place in roller mills and the size to which the solid residue is ground depends on the distance between the two shafts.

The milled solid residue falls onto a belt conveyor for removal of carbon. It has two sections horizontal (27) and sloping (28) and after its outlet, the carbon is stored in containers and used as intended. The yield of the solid carbon is $400 \mathrm{~kg} / \mathrm{h}$. A magnetic separator positioned on the horizontal section of the conveyor is used to separate the metal particles from the solid residue. The metal particles are extracted from carbon through magnetic induction and stored. The yield of the metal obtained by separation with the magnetic separator is $100 \mathrm{~kg} / \mathrm{h}$. 
The pyrolysis gas is discharged from the boiler via outlet pipes (6) and enters the mixing heat exchanger (8), a general view of which is shown in fig 4 . The gas is cooled there by mixing with the liquid fuel obtained after condensation of the same pyrolysis gas. The liquid fuel with a temperature of $30^{\circ} \mathrm{C}$ and a mass flow of $1980 \mathrm{~kg} / \mathrm{h}$ is injected into the hot gas and evaporates, cooling the gas. The supply of liquid fuel to the heat exchanger (8) takes place via three inlets distributed at three levels over its apparatus height for more even spread. The cooled pyrolysis gas with a temperature of $150^{\circ} \mathrm{C}$ leaves the upper end of the heat exchanger and enters the next module - condenser with a water jacket (9). The general view of this apparatus is shown in Figure 5. Part of the pyrolysis gas cooled by cold water condenses as it passes along the entire length of the condenser and flows to the outlet. A mixture from liquid and gaseous fuel with a temperature of $40^{\circ} \mathrm{C}$ leaves the condenser outlet, as the ratio between the liquid and the gaseous fuel is $2380: 100 \mathrm{~kg} / \mathrm{h}$. The cooling fluid in the condenser is water that enters it at a temperature of $30^{\circ} \mathrm{C}$ and a flow rate of $1692 \mathrm{~kg} / \mathrm{h}$ and leaves it at a temperature of $70^{\circ} \mathrm{C}$.

A gas/liquid separator (10) is installed after the condenser (9). It completely separates the liquid and the gaseous parts of the fuel. The liquid fuel, separated from the lower end of the separator, enters the intermediate fuel tank (19). It is intended to reduce the temperature of the liquid fuel and to distribute it. One part of the liquid fuel with a flow rate of $1980 \mathrm{~kg} / \mathrm{h}$ is returned to the mixing heat exchanger (8), and the rest part through the fuel pump (21) is fed to the fuel filter (23) and collected in the liquid fuel tank (24). The liquid fuel directed to the heat exchanger (8) is sucked in by the fuel circulation pump and cooled in the fuel cooler (21) by a refrigerating machine to $30^{\circ} \mathrm{C}$ before entering the mixing heat exchanger (8).

The gaseous fuel is sucked in from the other outlet of the gas/liquid separator by an explosion-proof fan (11) and fed to a centrifugal separator (12) for separation of any liquid impurities and water droplets. After the centrifugal separator, the gaseous fuel is supplied to the gas receivers (13), where it is stored until it is drained for sale or to feed the gas burner of the pyrolysis boiler. The gaseous fuel line between the gas receivers and the gas burner is secured by an outlet of excess gas, equipped with a fire barrier (18).

The circulating water used for cooling the pyrolysis gas in the condenser and solid carbon residue in auger conveyor with water jacket (25) is collected in the water tank (17). The water is then sucked in by the circulation pump (16) and cooled from $70^{\circ} \mathrm{C}$ to $30^{\circ} \mathrm{C}$ in a heat exchanger (15) through a refrigerating machine. Then the water passes through a water filter and again enters the water jacket of the condenser. The circulation pump and water filter must be selected so as to provide the required flow rate of water of $2988 \mathrm{~kg} / \mathrm{h}$. The same refrigerating machine is used to cool the liquid fuel in the cooler 21 to a temperature of $30^{\circ} \mathrm{C}$ before being injected into the mixing heat exchanger.

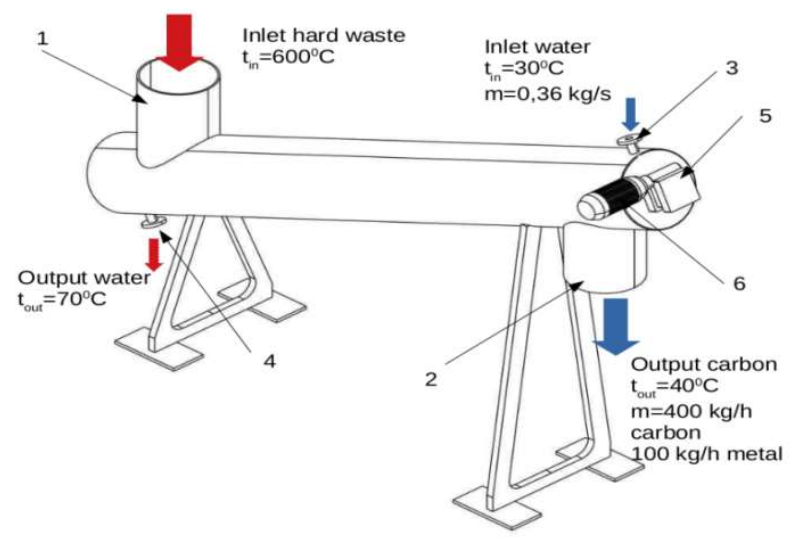

Fig. 3. General view of auger conveyor with a water jacket: 1 - inlet of the solid carbon residue; 2 - outlet of the solid carbon residue; 3 - inlet of cooling water; 4 - outlet of cooling water; 5 - reducer; 6 - electric motor 


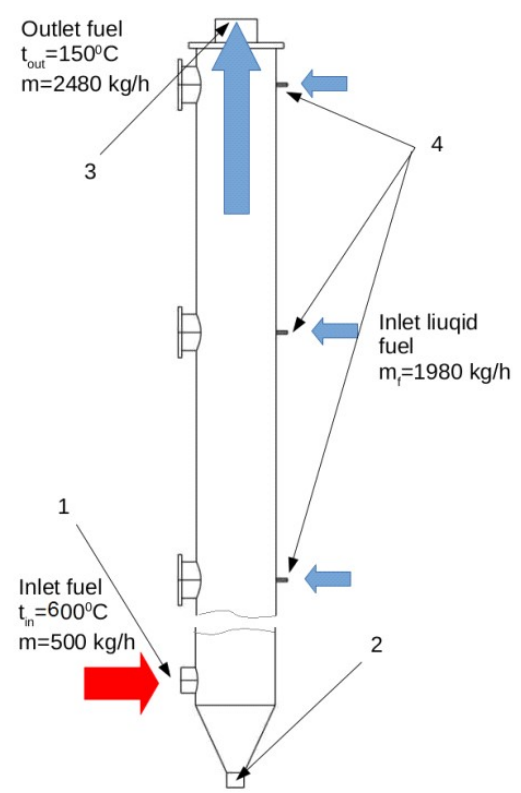

Fig. 4. General view of mixing heat exchanger: 1, 3 - pyrolysis gas inlet and outlet; 2 - drainage outlet; 4 - liquid fuel inlet pipes

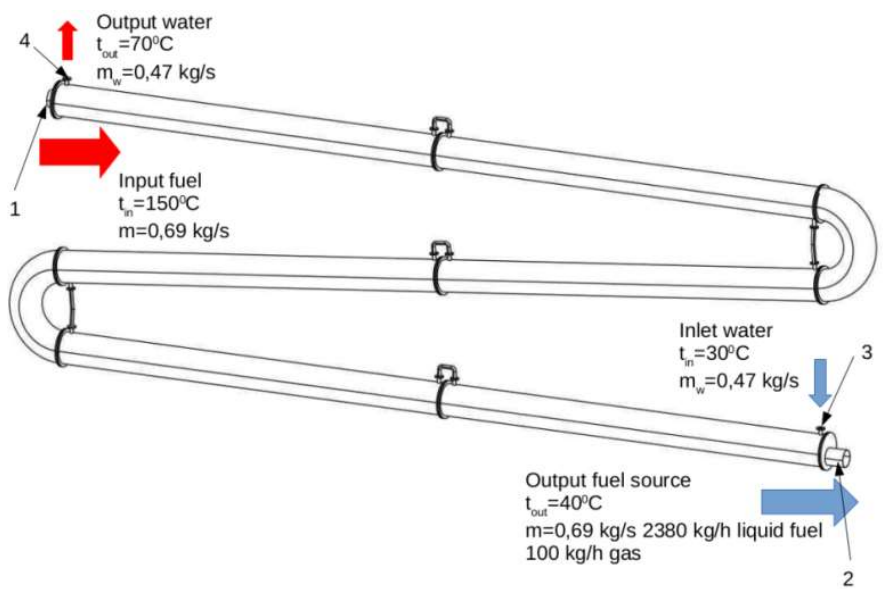

Fig. 5. General view of condenser with water jacket: 1 - pyrolysis gas inlet; 2 - outlet for fuel mixture; 3 - cooling water inlet; 4 - cooling water outlet

\section{Materials and energy recovered from ELTs}

Material balance: $400 \mathrm{~kg}$ of liquid fuel, $100 \mathrm{~kg}$ of gaseous fuel, $100 \mathrm{~kg}$ of metal and $400 \mathrm{~kg}$ of carbon residue are obtained from 1 ton of ELTs treated by pyrolysis in the presented installation.

The gaseous fuel produced as a result of pyrolysis is used as a fuel for the gas burner of the pyrolysis boiler in the same plant. For this reason, it must be ensured that the burner is powered by an external source until gas is generated from the pyrolysis plant.

Liquid fuel has parameters similar to the diesel oil and is suitable for transport. It could be used as additives to other liquid fuels, or as a source for production of various chemical products. 
The carbon obtained is applied in industry, such as different fillers for many products, concrete, plastics, etc, or for the production of activated carbon. The metal residue is delivered as secondary raw materials for subsequent recycling processing.

The material and energy flows necessary for the proposed pyrolysis installation are:

Energy balance of mixing heat exchanger is shown by the equation (1)

$$
H_{g}^{i n}+H_{o i l}^{i n}=H_{g}^{o u t}+Q_{\text {loss }}
$$

Enthalpy of pyrolysis gas entering heat exchanger, enthalpy of pyrolysis gas leaving heat exchanger and enthalpy of pyrolysis oil entering heat exchanger are represented by equations (2), (3) and (4) respectively. $Q_{\text {loss }}$ is heat loss to the outside air in $\mathrm{kW}$.

$$
\begin{gathered}
H_{g}^{\text {in }}=m_{g}^{\text {in }} \times c_{g} \times T_{g}^{\text {in }}=\frac{500}{3600} \times 1.382 \times 600=115.17 \mathrm{~kW} \\
H_{g}^{\text {out }}=m_{g}^{\text {out }} \times c_{g} \times T_{g}^{\text {out }}=\frac{2480}{3600} \times 1.382 \times 150=142.81 \mathrm{~kW} \\
H_{\text {oil }}^{\text {in }}=m_{\text {oil }}^{\text {in }} \times c_{\text {oil }} \times T_{\text {oil }}^{\text {in }}=\frac{1980}{3600} \times 1.848 \times 30=30.49 \mathrm{~kW}
\end{gathered}
$$

where $m_{g}^{\text {in }}, m_{g}^{\text {out }}$ and $m_{\text {oil }}^{\text {in }}$ are mass flows of pyrolysis gas entering heat exchanger, pyrolysis gas leaving heat exchanger and pyrolysis oil entering heat exchanger, $\mathrm{kg} / \mathrm{s}$;

$c_{g}$ and $c_{\text {oil }}$ is specific heat capacity of pyrolysis gas and oil respectively, $\mathrm{kJ} /(\mathrm{kg} . \mathrm{K})$ [29];

$T_{g}^{\text {in }}, T_{g}^{\text {out }}$ and $T_{\text {oil }}^{\text {in }}$ is temperature of inflow pyrolysis gas, outflow pyrolysis gas and inflow pyrolysis oil, ${ }^{0} \mathrm{C}$.

The heat flux removed by the pyrolysis gas in condenser - $Q_{1}$ is calculated by the energy balance of the pyrolysis gas side in the condenser - equation (5), where enthalpy of pyrolysis gas entering condenser, enthalpy of pyrolysis gas leaving condenser and enthalpy of pyrolysis oil leaving condenser are represented by equations (6), (7) and (8) respectively.

$$
\begin{gathered}
H_{g 1}^{\text {in }}=H_{g 1}^{\text {out }}+H_{\text {oil } 1}^{\text {out }}+Q_{1} \rightarrow Q_{1}=92.4 \mathrm{~kW} \\
H_{g 1}^{\text {in }}=m_{g 1}^{\text {in }} \times c_{g} \times T_{g 1}^{\text {in }}=\frac{2480}{3600} \times 1.382 \times 150=142.8 \mathrm{~kW} \\
H_{g 1}^{\text {out }}=m_{g 1}^{\text {out }} \times c_{g} \times T_{g 1}^{\text {out }}=\frac{100}{3600} \times 1.382 \times 40=1.53 \mathrm{~kW} \\
H_{\text {oil } 1}^{\text {out }}=m_{\text {oil } 1}^{\text {out }} \times c_{\text {oil }} \times T_{\text {oil } 1}^{\text {out }}=\frac{2380}{3600} \times 1.848 \times 40=48.87 \mathrm{~kW}
\end{gathered}
$$

where $m_{g 1}^{\text {in }}, m_{g 1}^{\text {out }}$ and $m_{\text {oil } 1}^{\text {out }}$ are mass flows of pyrolysis gas entering condenser, pyrolysis gas leaving condenser and pyrolysis oil living condenser, $\mathrm{kg} / \mathrm{s}$;

$T_{g 1}^{\text {in }}, T_{g 1}^{\text {out }}$ and $T_{\text {oil1 }}^{\text {out }}$ is temperature of inflow pyrolysis gas, outflows pyrolysis gas and pyrolysis oil, ${ }^{0} \mathrm{C}$.

The heat flux absorbed by the cooling water in the condenser $-Q_{2}$ is calculated by the energy balance of the water side in the condenser - equation (9), where enthalpy of cooling water entering condenser, enthalpy of cooling water leaving condenser and heat loss to the outside air - $Q_{l o s s, c}$ are represented by equations (10), (11) and (12) respectively.

$$
\begin{gathered}
H_{w}^{\text {in }}+Q_{2}=H_{w}^{\text {out }} \rightarrow Q_{2}=78.77 \mathrm{~kW} \\
H_{w}^{\text {in }}=m_{w}^{\text {in }} \times c_{w} \times T_{w}^{\text {in }}=\frac{1692}{3600} \times 4.19 \times 30=59.08 \mathrm{~kW} \\
H_{w}^{\text {out }}=m_{w}^{\text {out }} \times c_{w} \times T_{w}^{\text {out }}=\frac{1692}{3600} \times 4.19 \times 70=137.85 \mathrm{~kW}
\end{gathered}
$$




$$
Q_{1}=Q_{2}+Q_{\text {loss }, c}
$$

where $m_{w}^{i n}$ and $m_{w}^{o u t}$ are mass flows of cooling water entering and leaving condenser, $\mathrm{kg} / \mathrm{s}$;

$c_{w}$ is specific heat capacity of cooling water, $\mathrm{kJ} /(\mathrm{kg} . \mathrm{K})$;

$T_{w}^{\text {in }}$ and $T_{w}^{\text {out }}$ is temperature of inflow and outflow cooling water, ${ }^{0} \mathrm{C}$.

The heat flux removed by the solid carbon residue in cooling heat exchanger $-Q_{1 r}$ is calculated by the energy balance of the carbon residue side in the heat exchanger - equation (13), where enthalpy of carbon residue entering heat exchanger, enthalpy of char and metal residue leaving heat exchanger are represented by equations (14), (15) and (16) respectively.

$$
\begin{gathered}
H_{r}^{\text {in }}=H_{c h}^{\text {out }}+H_{m}^{\text {out }}+Q_{1 r} \rightarrow Q_{1 r}=60.88 \mathrm{~kW} \\
H_{r}^{\text {in }}=m_{r}^{\text {in }} \times c_{r} \times T_{r}^{\text {in }}=\frac{500}{3600} \times 0.783 \times 600=65.23 \mathrm{~kW} \\
H_{c h}^{\text {out }}=m_{c h}^{\text {out }} \times c_{c h} \times T_{c h}^{\text {out }}=\frac{400}{3600} \times 0.853 \times 40=3.79 \mathrm{~kW} \\
H_{m}^{\text {out }}=m_{m}^{\text {out }} \times c_{m} \times T_{m}^{\text {out }}=\frac{100}{3600} \times 0.5 \times 40=0.56 \mathrm{~kW}
\end{gathered}
$$

where $m_{r}^{\text {in }}, m_{c h}^{\text {out }}$ and $m_{m}^{\text {out }}$ are mass flows of solid carbon residue entering heat exchanger, char leaving heat exchanger and metal residue living heat exchanger respectively, $\mathrm{kg} / \mathrm{s}$;

$c_{r}, c_{c h}$ and $c_{m}$ is specific heat capacity of solid carbon residue, char and metal residue respectively, $\mathrm{kJ} /(\mathrm{kg} . \mathrm{K})$;

$T_{r}^{\text {in }}, T_{c h}^{\text {out }}$ and $T_{m}^{\text {out }}$ is temperature of inflow solid carbon residue, outflows char and metal residue respectively, ${ }^{0} \mathrm{C}$.

The heat flux absorbed by the cooling water in the heat exchanger cooling solid carbon residue $-Q_{2 r}$ is calculated by the energy balance of the water side in the heat exchanger equation (17), where enthalpy of cooling water entering and leaving heat exchanger and heat loss flux to the outside air are represented by equations (18), (19) and (20) respectively.

$$
\begin{gathered}
H_{w r}^{\text {in }}+Q_{2 r}=H_{w r}^{\text {out }} \rightarrow Q_{2 r}=60.34 \mathrm{~kW} \\
H_{w r}^{\text {in }}=m_{w r}^{\text {in }} \times c_{w} \times T_{w r}^{\text {in }}=\frac{1296}{3600} \times 4.19 \times 30=45.25 \mathrm{~kW} \\
H_{w r}^{\text {out }}=m_{w r}^{\text {out }} \times c_{w} \times T_{w r}^{\text {out }}=\frac{1296}{3600} \times 4.19 \times 70=105.59 \mathrm{~kW} \\
Q_{1 r}=Q_{2 r}+Q_{\text {loss }, r}
\end{gathered}
$$

where $m_{w r}^{\text {in }}$ and $m_{w r}^{\text {out }}$ are mass flows of cooling water entering and leaving heat exchanger respectively, $\mathrm{kg} / \mathrm{s}$;

$T_{w}^{\text {in }}$ and $T_{w}^{\text {out }}$ is temperature of inflow and outflow cooling water respectively, ${ }^{0} \mathrm{C}$.

The heat flux released by the pyrolysis gas combustion in the pyrolysis boiler $-Q_{\text {in }}$ is calculated by the equation (21).

$$
Q_{\text {in }}=m_{b, g} \times Q_{b, g}=\frac{1296}{3600} \times 4.19=358,6 \mathrm{~kW}
$$

where $m_{b, g}$ is mass flow of pyrplysis gas burning in boiler, $\mathrm{kg} / \mathrm{s}$;

$Q_{b, g}$ is calorific value of pyrolysi gas, $\mathrm{kJ} / \mathrm{kg}$ [29];

In general, the following resources are required for the operation of the pyrolysis installation: circulating water with a flow rate of $2988 \mathrm{~kg} / \mathrm{h}$ and $139 \mathrm{~kW}$ of electricity power for operation of cooling water refrigeration machine and circulation pumps and the fan. The 
heat of the circulating water could be used for space heating or domestic hot water. This will reduce the energy consumption of the refrigerator.

\section{Conclusion}

The proposed installation for pyrolysis of ELTs has been implemented into real operation. It is a good option for recovery of valuable materials and energy from waste such as ELTs.

Due to decomposition of hazardous tires in pyrolysis process and the use of the resulting pyrolysis gases to produce liquid and gaseous fuels, the system proves to be an environmentally friendly source of heat and energy.

The fuels obtained in the plant are recyclable energy sources and can be used as percentage additives to standard fuels or used directly.

Various products or activated carbon could be made from the obtained carbon residue, and the metal could be used to produce various steels and cast irons.

The operation of this pyrolysis plant leads to reduction in the amount of ELTs in landfills and to protection of the environment and human health.

\section{References}

1. https://www.consilium.europa.eu/media/41768/12-euco-final-conclusions-en.pdf, European Council meeting (12 December 2019)

2. N. El Bassam, P. Maegaard, and M. L. Schlichting, Current distributed renewable energy rural and urban communities, Distributed Renewable Energies for Off-Grid Communities (2013)

3. G. Lazaroiu, V. Berbece, L. Mihaescu, I. Pisa, G.-P. Negreanu, Biogas production from animal protein waste, an environmental protection technology coupled with energy production, Scientific Works of University of Food Technologies- Plovdiv, Volume 64, Issue 1, (2017)

4. S. Dichev, Y. Lambrev, Application and perspectives for use of heat pumps in industry, Scientific Works of University of Food Technologies - Plovdiv, Vol. XLIII, Issue 3 (1998) (in Bulgarian)

5. G. Raichkov, M. Valchev, M. Georgieva, Permanent ventilation of rooms and buildings - factor of healthy comfort, J. Heattecnics, No. 6, Year 5, Book 1, TU-Varna, (2014) (in Bulgarian)

6. Council Directive 1999/31/EC on the landfill of waste, Official Journal of the European Communities (1999)

7. Directive 2006/12/EC of the European Parliament and of the Council on waste, Official Journal of the European Union (2006)

8. Directive 2008/98/EC of the European Parliament and of the Council on waste and repealing certain Directives (2008)

9. M.R. Sebola, P.T. Mativenga, J. Pretorius, A benchmark study of waste tyre recycling in south africa to European union practice, Procedia CIRP 69 (2018), 950-955

10. Waste Management Act (2012) https://www.moew.government.bg/static/media/ ups/tiny/УOОП/Законодателство/WASTE MANAGEMENT ACT_13.pdf

11. T.A. Mallah, A.R. Sahito, Optimization of castor and neem biodiesel blends and development of empirical models to predict its characteristics, Fuel (2020),

12. K. Georgiev, I. Evtimov, R. Ivanov, Analytical study on wearing of pneumatic tires of wheeled machines, Proceedings of Scientific conference with international participation 
"Transport, Ecology - Sustainable Development", Varna (2013), 13-17, (in Bulgarian)

13. R. Ivanov, K. Georgiev, G. Kadikyanov, G. Staneva, An experimental research on the wear of truck tire, Poland, SJ Transport Problems, Vol. 10, Issue 4 (2015), 91-98

14. K. Georgiev, R. Ivanov, G. Kadikianov, G. Staneva, Analytical study of the effect of tire air pressure on tire wear, Proceedings of International Scientific Conference BulTrans, Sozopol, (2015), 113-116

15. R.K. Singh, B. Ruj, A.K. Sadhukhan P. Gupta, Energy recovery from tyre waste pyrolysis: product yield analysis and characterization, Energy Recovery Processes from Wastes, Springer Nature Singapore Pte Ltd., (2020)

16. V. Torretta, E.C. Rada, M. Ragazzi, E. Trulli, I.A. Istrate, L.I. Cioca, Treatment and disposal of tyres: two EU approaches. A review, Waste Management 45 (2015) 152-160

17. H.-Ho Tsang, Uses of scrap rubber tires, Rubber: types, properties and uses, 2010 Nova Science Publishers, Inc. (2019)

18. C. Bulei, M. P. Todor, T. Heput, I. Kiss, Directions for material recovery of used tires and their use in the production of new products intended for the industry of civil construction and pavements, Materials Science and Engineering 294 (2018)

19. B. Savary, R. Vincent, Used tire recycling to produce granulates: Evaluation of occupational exposure to chemical agents, Ann. Occup. Hyg., Vol. 55, No. 8 (2011), 931-936

20. A. Ayanog lu, R. Yumrutas, Production of gasoline and diesel like fuels from waste tire oil by using catalytic pyrolysis, Energy (2016)

21. P.T. Williams, A.J. Brindle, Fluidised bed catalytic pyrolysis of scrap tyres: Influence of catalyst:tyre ratio and catalyst temperature, Waste Manag. Res. 20 (2002), 546-555

22. J.D. Martínez, N. Puy, R. Murillo, T. García, M.V. Navarro, A.M. Mastral, Waste tyre pyrolysis - a review, Renew. Sustain. Energy Rev. (2013)

23. D. Perondi B. Santinon Scopel G. Carvalho Collazzo J. Pessutto Silva M. Leoratto Botomé A. Dettmer M. Godinho A.C Faria Vilela, Characteristics of pyrolysis products from waste tyres and spent foundry sand co-pyrolysis Prog. Rubber, Plast. Recycl. Technol. 32 (2016), 213-240

24. C.F.S. Rombaldo, A.C.L. Lisbôa, M.O.A. Méndez, A. dos R. Coutinho, Effect of Operating Conditions on Scrap Tire Pyrolysis, Mat. Res. vol. 11 no. 3 (2008)

25. D.Ab. Taleb, H.A. Hamid, R.R.R. Deris, M. Zulkifli, N.A. Khalil, A.N.A. Yahaya, Insights into Pyrolysis of Waste Tire in Fixed Bed Reactor: Thermal Behavior, Materials today: Proceedings - February (2020), doi: 10.1016/j.matpr.2020.01.569

26. M. Ryms, K. Januszewicz, W.M. Lewandowski, E. Klugmann-Radziemska, Pyrolysis Process of Whole Waste Tires as a Biomass Energy Recycling, Ecol Chem Eng S., 20(1) (2013), 93-107

27. S. Kordoghli, M. Paraschiv, R. Kuncser, M. Tazerout, M. Prisecaru, F. Zagrouba, I. Georgescu, Managing the Environmental Hazards of Waste Tires, Journal of Engineering Studies and Research, Volume 20, No. 4 (2014)

28. G. Komitov, V. Rasheva, I. Binev, I. Kiryakov, Innovation technology for using of disposals automobile tyres, European Journal of technical and natural science, Vol.4, Vienna (2016), 20-22

29. D. Chakarova, A. Andreev. Energy and exergy analysis of pyrolysis of waste tires, Proceedings of the XXI Scientific Conference EMF'2016, TU-Sofia, (2016), (in Bulgarian) 